\title{
Sun and planets from a climate point of view
}

\author{
J. Beer, J. A. Abreu and F. Steinhilber \\ Swiss Federal Institute of Aquatic Science and Technology, Eawag, 8600 Dübendorf, \\ Switzerland
}

\begin{abstract}
The Sun plays a dominant role as the gravity centre and the energy source of a planetary system. A simple estimate shows that it is mainly the distance from the Sun that determines the climate of a planet. The solar electromagnetic radiation received by a planet is very unevenly distributed on the dayside of the planet. The climate tries to equilibrate the system by transporting energy through the atmosphere and the oceans provided they exist. These quasi steady state conditions are continuously disturbed by a variety of processes and effects. Potential causes of disturbance on the Sun are the energy generation in the core, the energy transport trough the convection zone, and the energy emission from the photosphere. Well understood are the effects of the orbital parameters responsible for the total amount of solar power received by a planet and its relative distribution on the planet's surface. On a planet, many factors determine how much of the arriving energy enters the climate system and how it is distributed and ultimately reemitted back into space. On Earth, there is growing evidence that in the past solar variability played a significant role in climate change.
\end{abstract}

Keywords. Sun: activity, (Sun:) solar-terrestrial relations, atmospheric effects

\section{Introduction}

Climate can be defined as "the prevalent or characteristic meteorological conditions (temperature, pressure, water vapour etc.) of any place or region and their extremes". It is a complex non-linear dynamic system with a large spatial and temporal variability. Since it is impossible to discuss all aspects of climate in a short paper we concentrate here on a few basic considerations which apply to all planets. Basically, the climate can be considered as a machine which is driven by solar energy. Its main purpose is to equally distribute the incoming energy over the planet. Depending on the distance from the Sun, solar luminosity and planetary albedo, a simple estimate of the mean surface temperature of a planet can be made assuming steady state conditions. Then we address the question which processes potentially cause climate variability. Finally we provide some evidence for solar forcing of climate change on Earth.

\section{Steady state climate conditions}

The energy driving the climate machine on a planet stems to almost $100 \%$ from the Sun. By turning every second some 4.2 million tons of mass into energy the Sun generates a power of $2 \cdot 10^{27} \mathrm{~W}$ which is radiated into space. Fusing hydrogen into helium in the core the Sun is able to maintain this huge power generation for almost 10 billion years. The standard solar model shows that the luminosity is steadily increasing from about $80 \%$ of its present values $4 \mathrm{Gyr}$ ago to about $130 \%$ in $4 \mathrm{Gyr}$ from now. According to this model the change occurs very smoothly and slowly $\left(10^{-8} \%\right.$ per year $)$ as shown in Fig. 1.

Other sources of energy on planets are cosmic rays, geothermal energy as a result of radioactive decay and gravitational energy from the time of formation of the solar system, 


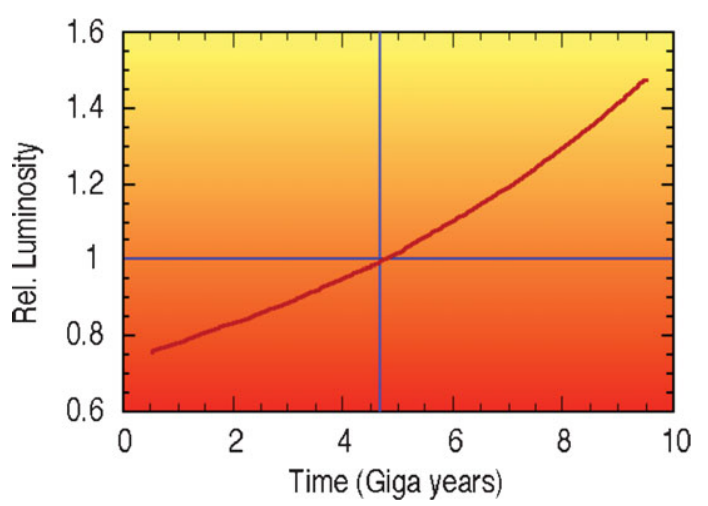

Figure 1. Luminosity of the Sun according to the standard solar model in units relative to the present (Newkirk 1983).

tidal energy from moons, and in some cases gravitational energy released by compression (Jupiter). In the case of the Earth these contributions amount to $10^{10} \mathrm{~W}, 10^{13} \mathrm{~W}, 10^{11} \mathrm{~W}$, and $0 \mathrm{~W}$ respectively, compared to the $10^{17} \mathrm{~W}$ obtained from the Sun. The solar power received by a square meter of a planet depends on the angle of incidence. On Earth it decreases with the cosine of the latitude. This leads to a thermal gradient between low and high latitudes. The climate machine tries to reduce this gradient by transporting energy polewards. Three different mechanisms come into play (Fig. 2): sensible heat flux, latent heat flux and surface heat flux.

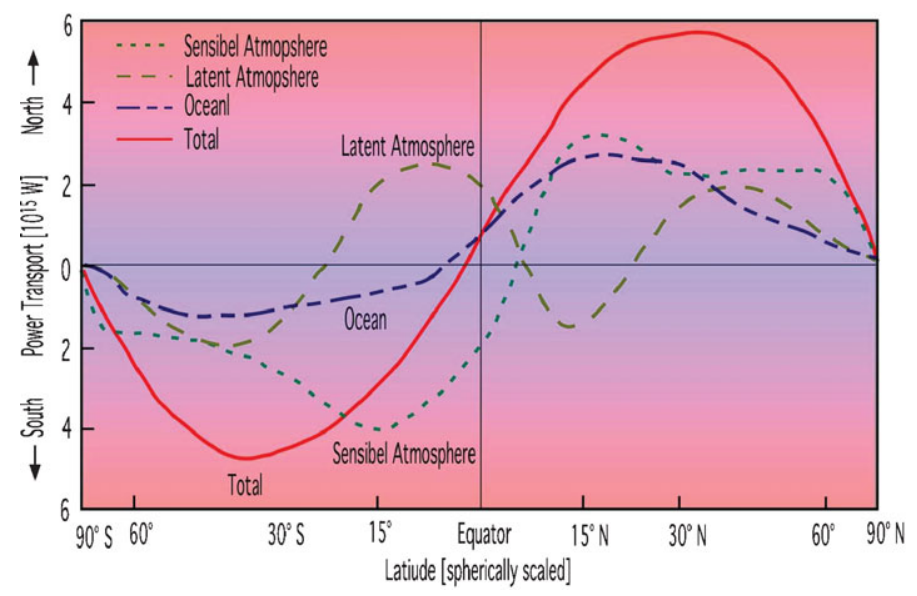

Figure 2. Meridional heat transport on Earth consisting of sensible and latent heat flux through the atmosphere and heat flux through the oceans. The total heat flux is largest between $15^{\circ}$ and $60^{\circ}$ latitude for both hemispheres (modified after Bryden and Imawaki 2001).

The sensible heat flux transfers the energy from the planet's surface to the atmosphere by conduction and convection. Then atmospheric circulation transports the energy advectively by moving warm tropical air towards the colder Polar Regions. Latent heat is generated when solid and liquid water is converted into water vapour. This vapour takes part in the atmospheric circulation. When it reaches colder regions the vapour condenses to rain and snow releasing the stored heat again. Finally the surface heat flux consists of warm ocean water flowing polewards in the form of huge streams (e.g. Gulf Stream). Evaporation and sea ice formation generate cold and saline surface water. This dense 
water descends to greater depth where it flows towards the equator closing the circle. All three processes are affected by a variety of processes such as the distribution of the continents and the Coriolis force. This leads to complex transport patterns. If a planet has no atmosphere and no water the temperature gradient between low and high latitudes can be large. Without this energy transport for example on Earth the Polar Regions would be colder by $25^{\circ} \mathrm{C}$ and the equatorial regions would be warmer by about $15^{\circ} \mathrm{C}$.

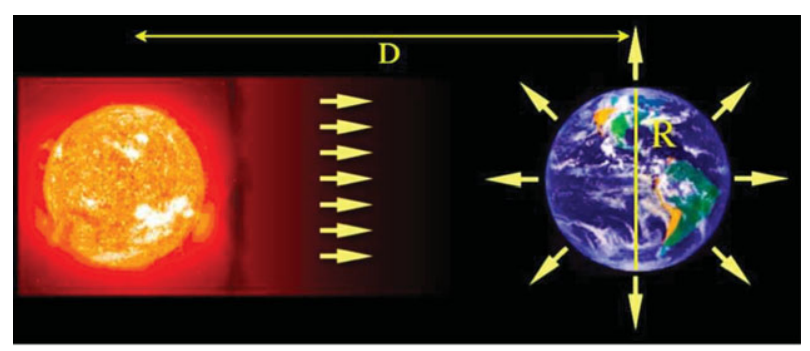

Figure 3. Radiation balance between the Sun and a planet.

Fig. 3 shows a planet with the radius $R$ and the albedo $a$ in the distance $D$ from the Sun with the luminosity $L$. The power absorbed by a planet is given by the ratio of the planets cross section $\pi R^{2}$ to the power in the distance $D$ from the Sun $4 \pi D^{2}$ corrected for the albedo $a$ (total reflected power):

$$
P_{\mathrm{abs}}=(1-a) L \frac{\pi R^{2}}{4 \pi D^{2}}
$$

If we assume as a first approximation that a planet is a black body and that the incoming solar radiation is equally distributed by the climate machine, the emitted power is given by the law of Stefan-Boltzmann:

$$
P_{\mathrm{emi}}=4 \pi R^{2} \sigma T^{4}
$$

In the case of equilibrium, absorption and emission are equal and the temperature $T$ can be calculated:

$$
T=\sqrt[4]{\frac{L(1-a)}{16 \pi D^{2} \sigma}}
$$

Note that the temperature of a planet does not depend on its size. Under the given assumptions it is only determined by the solar luminosity, the albedo, and the distance from the Sun. Fig. 4 shows the dependence of a planet's temperature on the distance for different albedos (upper panel) and luminosities (lower panel). The distance is given in astronomical units $(\mathrm{AU})$ covering the range of the planets from $0.38 \mathrm{AU}$ (Mercury) to $30 \mathrm{AU}$ (Neptune). The luminosity is given in units relative to the present. In the upper panel the luminosity is set to 1 (present value) and in the lower panel an albedo of 0.3 is assumed.

In Table 1 the calculated temperatures for the 8 planets are compared to the measured ones. For each planet a lower value with an albedo of 0.5 and a luminosity of 0.8 , an average value with $a=0.3$ and $L=1$, and an upper limit with $a=0.1$ and $L=1.3$ are given.

Overall there is a reasonable agreement between the estimated and the observed temperatures. The largest discrepancy is observed for Venus. The reason is that Venus has a very dense atmosphere which consists of $96 \%$ of $\mathrm{CO}_{2}$ with clouds of $\mathrm{SO}_{2}$ generating the strongest greenhouse effect in the solar system. In the case of Earth the difference between calculated (using the present values $a=0.3$ and $L=1$ ) and measured mean global 


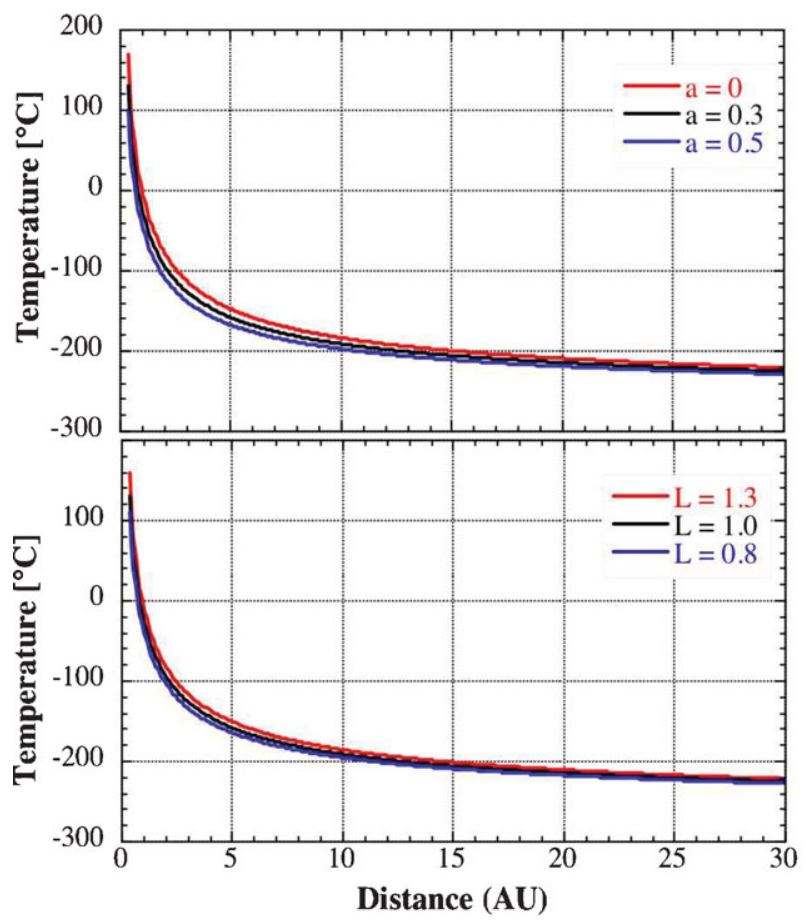

Figure 4. Dependence of planetary temperatures on the distance from the Sun for different values of the albedo $a$ (upper panel) and luminosity $L$ (lower panel).

Table 1. Comparison of the calculated temperatures of the planets for different combinations of albedo and luminosity are compared with the observed temperatures.

\begin{tabular}{|c|c|c|c|c|c|}
\hline \multirow[b]{2}{*}{ Planet } & \multirow[b]{2}{*}{$\begin{array}{r}\text { Distance } \\
(\mathrm{AU})\end{array}$} & \multirow[b]{2}{*}{$\begin{array}{l}a=0.5 \\
L=0.8\end{array}$} & \multicolumn{2}{|c|}{ Temperature $\left({ }^{\circ} \mathrm{C}\right)$} & \multirow[b]{2}{*}{ Observed } \\
\hline & & & $\begin{array}{r}a=0.3 \\
L=1\end{array}$ & $\begin{array}{l}a=0.1 \\
L=1.2\end{array}$ & \\
\hline Mercury & 0.38 & 77 & 130 & 175 & -180 to 420 \\
\hline Venus & 0.72 & -10 & 30 & 66 & 460 \\
\hline Earth & 1 & -50 & -18 & 11 & 15 \\
\hline Mars & 1.52 & -95 & -65 & -40 & -87 to 5 \\
\hline Jupiter & 5.2 & -175 & -160 & -150 & -130 \\
\hline Saturn & 9.54 & -200 & -190 & -180 & -180 \\
\hline Uranus & 19.18 & -220 & -215 & -210 & -210 \\
\hline Neptune & 30.06 & -230 & -225 & -220 & -210 \\
\hline
\end{tabular}

temperature is $33^{\circ} \mathrm{C}$. This difference is also due to the natural greenhouse effect. It is important to note that the Earth needs the natural greenhouse effect to be habitable, but not necessarily an additional anthropogenic increase. The range of observed temperatures on Mars is very large because Mars has only a very thin atmosphere $(0.3 \mathrm{hPa}$ compared to $1000 \mathrm{hPa}$ of Earth) and no liquid water to transport energy. Jupiter is considerably warmer than calculated $\left(-110^{\circ} \mathrm{C}\right.$ instead of $\left.-160^{\circ} \mathrm{C}\right)$. Most likely, this difference is due to gravitational compression which provides an additional power at least as large as the solar insolation. In fact, doubling the solar luminosity in formula (2.3) leads to a temperature of about $-130^{\circ} \mathrm{C}(a=0.3)$ in agreement with the observed value at the top of the clouds.

After having discussed the total amount of power received by a planet we address now the question of the distribution of this power on the planet. The distribution is mainly 
determined by the orbital parameters. Rotation plays a central role in distributing energy. If the axis of rotation is not perpendicular to the ecliptic plane the daily path of the Sun in the sky changes during one orbit giving rise to the seasons on Earth. Finally if the planet orbits around the Sun are elliptical, the distance from the Sun varies continuously and affects accordingly the total power received by the planet. Presently the distance between Sun and Earth varies by $3.4 \%$ during the course of a year causing a variation in the Total Solar Irradiance (TSI) of $87 \mathrm{Wm}^{-2}$.

\section{Climate variability}

So far we have assumed that all the conditions determining the climate of a planet are constant. Obviously this is not the case in reality. There are many different sources of variability which ultimately cause deviations from the steady state conditions or, in other words, climate variability. If we stick to our simplified approach by formula (2.3) we already know that the temperature of a planet depends strongly on the luminosity, the distance from the Sun, and the albedo. We discuss now potential changes in these parameters.

\subsection{Luminosity}

The luminosity is the total power emitted by the Sun. Fig. 1 shows that the luminosity increase is very slow and smooth. This is due to the fusion process in the core which is very stable on time scales of millennia. The low luminosity after the formation of the solar system about 4 Gyr ago poses an interesting question called the "faint young sun paradox". According to formula (2.3) a reduction of the luminosity by $25 \%$ leads to a decrease of the mean global temperature on Earth by $18^{\circ} \mathrm{C}$. Under the present conditions such a temperature drop would turn the Earth into a "snowball" with a much larger albedo. This would make a return to normal conditions rather impossible. The generally accepted main reason why this did not happen is a higher content of greenhouse gases in the atmosphere at that time. From the derivation of formula (2.3) we obtain:

$$
\mathrm{d} T / T=(1 / 4) \mathrm{d} L / L .
$$

The relative change in temperature is $1 / 4$ of the relative change in $L$. In other words a change of $L$ of $0.1 \%$ as typically measured between solar minimum and maximum during an 11-y Schwabe cycle corresponds to a temperature change of the photosphere of about $1.5 \mathrm{~K}$.

Other potential sources of luminosity changes are energy transport from the core to the solar surface and emission from the photosphere. From the core to about $2 / 3$ of the solar radius the energy is transported radiatively. Then convection becomes more efficient and brings the energy to the photosphere from where it is radiated into space. It is believed that the radiative energy transport is very stable. It is not known to what degree this is also true for the convective transport. However, it cannot be excluded that the magnetic fields generated by the dynamo at the tachocline below the convective zone have some influence on the convection (Kuhn 1988; Kuhn and Libbrecht 1991). The observed changes in the annual mean emission from the photosphere account for only about $0.1 \%$ during an 11-y Schwabe cycle (see Fig. 5) and therefore even very small fluctuations can have comparable effects.

By far, the largest part of the solar power is emitted by the photosphere in the form of electromagnetic radiation. The spectrum resembles that of a blackbody with a temperature of about $5780 \mathrm{~K}$. Only in the UV region of the spectrum there are larger contributions from very high temperatures in the corona, probably induced by reconnections of strong 
magnetic field lines. The total electromagnetic radiation arriving at the top of the Earth's atmosphere perpendicular to an area of $1 \mathrm{~m}^{2}$ at the distance of $1 \mathrm{AU}$ is called total solar irradiance (TSI). Its spectral distribution is called the solar spectral irradiance (SSI). Direct satellite based monitoring of the TSI over the past 30 years reveals clear variations in phase with the magnetic activity of the 11-y Schwabe cycle (Fig. 5) (Fröhlich and Lean 2004; Fröhlich 2006). The TSI curve is a composite of corrected data from five different instruments as indicated by different colours. There are three different composites based on different data and corrections. Although different in the long-term trend depending on the applied corrections and the used instruments, all composites show consistently lower values for the present solar minimum than for the previous one.

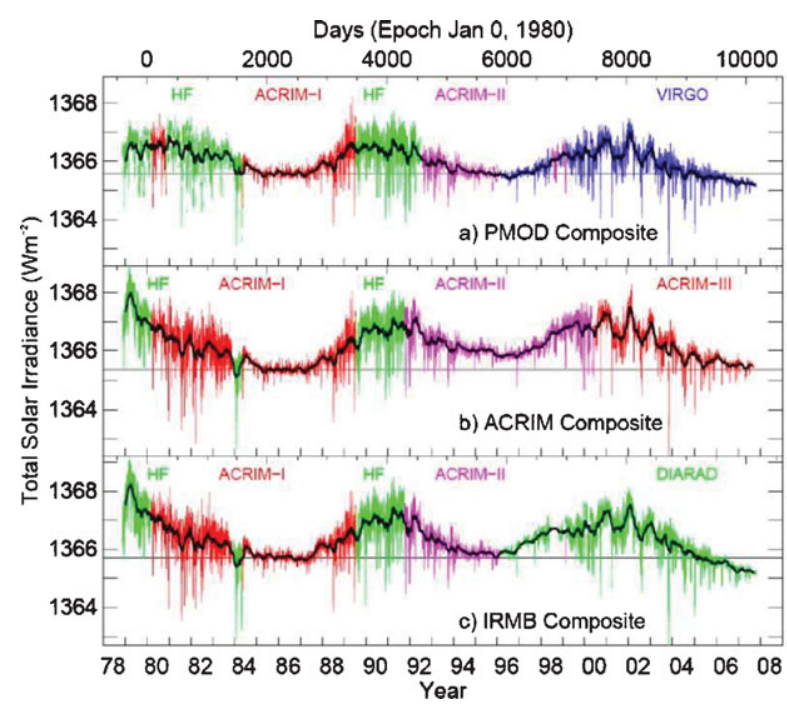

Figure 5. Three composites of the total solar irradiance (TSI) measured by 5 different satellite based radiometers indicated by different colours (The Picard Team, Dewitte, and Schmutz 2006; Lockwood and Fröhlich 2008; Fröhlich 2008; Willson and Mordvinov 2003). Due to composing different instruments and applying different corrections, the long-term trends are slightly different. However, for all composites the last minimum is lower than the previous one.

Simple models describing the TSI as the sum of a constant quiet sun component, a positive component due to bright faculae and the magnetic network, and a negative component composed of the dark sunspots and their penumbra are very successful in explaining all the observed short-term fluctuations (Krivova et al. 2003; Solanki and Fligge 2002; Unruh, Solanki, and Fligge 1999; Wenzler et al. 2006). However, it is not yet clear whether these models are also applicable to periods of much lower solar activity such as the Maunder minimum when almost no sunspots were observed for about 7 decades. The most recent decline since 2006 raises some serious doubts (Fröhlich 2008). Other potential sources of variability in the solar emission are changes in the solar radius and anisotropic emission. The solar radius is a crucial parameter (Sofia and Li 2005). However, observations did not provide clear evidence for changes in the radius so far (Thuillier, Sofia, and Haberreiter 2005). Clarification is expected from the Picard mission to be launched in 2009 (The Picard Team, Dewitte, and Schmutz 2006). Even without changes in the luminosity anisotropic emission of the total power can lead to changes in the TSI. The fact that sunspots and faculae are more prevalent at lower latitudes clearly points 
to an anisotropic emission. Whether this is also true for the solar disc free of visible magnetic activity, remains to be checked.

\subsection{Distance}

As we have already mentioned, the distance is the dominant parameter for the temperature of a planet. The first reason is that the solar power decreases with the square of the distance or in other words that the relative change of the temperature is $1 / 2$ of the relative change of the distance:

$$
\mathrm{d} T / T=(1 / 2) \mathrm{d} D / D
$$

The second reason is that the distance of the planets changes by almost 2 orders of magnitude from 0.38 AU (Mercury) to $30 \mathrm{AU}$ (Neptune).

Since all the planets have elliptical orbits the distance is continuously changing. The eccentricity (fraction of the distance along the semimajor axis at which the focus lies) ranges from 0.0068 of Venus to 0.2056 of Mercury. The situation is further complicated by the fact that the orbital parameters of a planet are disturbed by the gravitational forces of the other planets (mainly Jupiter and Saturn having the largest masses). The mathematical details of these disturbances have been worked out by Milankovic (Milankovic 1930) and more recently by Berger (Berger 1978) and Laskar (Laskar et al. 2004). The orbital parameters affected by the other planets are the eccentricity, the obliquity (the tilt angle of the planets axis relative to the ecliptic plane) and the precession of a planet's rotational axis around its mean direction. The calculations for the Earth reveal cyclic variability with characteristic time scales of 100 and $400 \mathrm{kyr}$ (eccentricity), $40 \mathrm{kyr}$ (obliquity) and 19-24 kyr (precession). While obliquity and precession change only the relative distribution of the solar insolation eccentricity changes affect the total insolation. Since the orbital parameters are very accurately known it is possible to calculate the insolation changes not only for the past several million years but also for the future. As an example Fig. 6 shows the orbital parameters, the insolation deviations in $\mathrm{Wm}^{-2}$ for June, December and the season (June minus December) from their corresponding mean values for the past $100 \mathrm{kyr}$ and the future $20 \mathrm{kyr}$. Note that, especially at high latitudes these deviations are very large (up to $80 \mathrm{Wm}^{-2}$ ) compared to the $2 \mathrm{Wm}^{-2}$ predicted for a doubling of the atmospheric $\mathrm{CO}_{2}$ concentration. However, it has to be considered that greenhouse gas forcing acts globally.

Figure 6 shows that the insolation in June was very low at $20 \mathrm{kyr}$ BP. This coincides with the last glacial maximum that is followed by a strong warming. The coming $20 \mathrm{kyr}$ are characterised by relatively small changes in orbital forcing. This relates to the decreasing trend in eccentricity which affects the seasonality.

To see how well the orbital forcing is reflected in paleoclimatic records we compare in Fig. 7 the $\delta^{18} \mathrm{O}$ record from the GRIP ice core drilled in central Greenland $\left(72^{\circ} \mathrm{N}\right)$ (Dansgaard et al. 1993) with the summer insolation at this latitude. $\delta^{18} \mathrm{O}$ is a measure of the atmospheric temperature when water vapour condenses and snow flakes form. The overall agreement between the two curves is good as far as the long-term trend is concerned. The glacial period is characterised by strong, very rapid changes (so-called Dansgaard-Oeschger events) that are most probably related to abrupt changes in the thermohaline circulation of the ocean. During the Holocene (the past $11 \mathrm{kyr}$ ) the climate was comparatively stable and has not clearly followed the insolation curve.

\subsection{Albedo}

The albedo is defined as the ratio of diffusely reflected to incident electromagnetic radiation and, therefore, lies in the interval $0-1$. It is difficult to determine the total albedo 

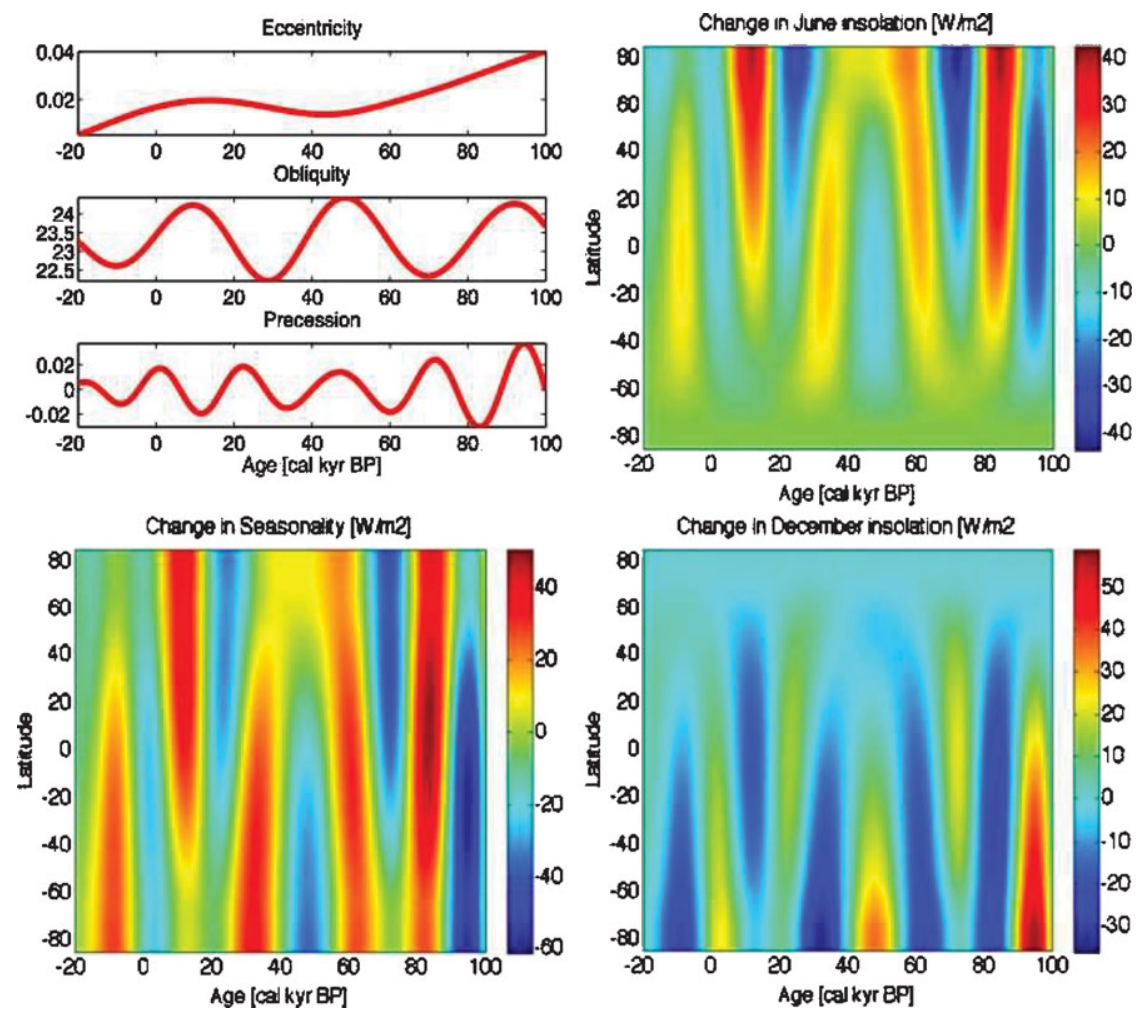

Figure 6. Changes in the orbital parameters of Earth (a) and their effect on the summer (June), the winter (December) and the seasonal (June-December) insolation for the past $100 \mathrm{kyr}$ and the future $20 \mathrm{kyr}(-20 \mathrm{kyr} \mathrm{BP})$. Shown are the deviations in $\mathrm{Wm}^{-2}$ from the mean values. Note the large changes at high latitudes.

of a planet because it is highly variable ranging from less than 0.1 for water and forests to more than 0.8 for fresh snow. On Earth, the largest contribution comes from the clouds which cover about $50 \%$ of its surface. For the Earth an albedo of 0.3 is usually assumed. Interestingly, the albedo gets much less attention than the TSI although both are equally important as far as solar forcing is concerned. The albedo of clouds plays a central role in the cosmic ray cloud hypothesis put forward by Danish scientists (Svensmark 1998). They claim that the Earth's cloud cover is modulated by the cosmic ray induced ion production in the atmosphere. Later they reduced the effect to low altitude, low latitude clouds (Marsh and Svensmark 2003). This issue is still debated in papers supporting (Usoskin et al. 2004) and contradicting (Kernthaler, Toumi, and Haigh 1999; Wagner et al. 2001) cosmic ray induced climate change. Other climate relevant effects related to strong atmospheric electrical currents have been proposed by Tinsley (Tinsley 2000). Although there is no doubt that many more different effects take place in the atmosphere there is so far no clear evidence that these processes play a significant role in global climate change (see also contribution by Usoskin in this volume).

\subsection{Aerosols}

Aerosols are liquid droplets or fine solid particles in the atmosphere that influence both directly and indirectly a planet's radiation budget. The direct effect is reflection and scattering of solar radiation back into space, leading to a cooling. As an indirect effect 


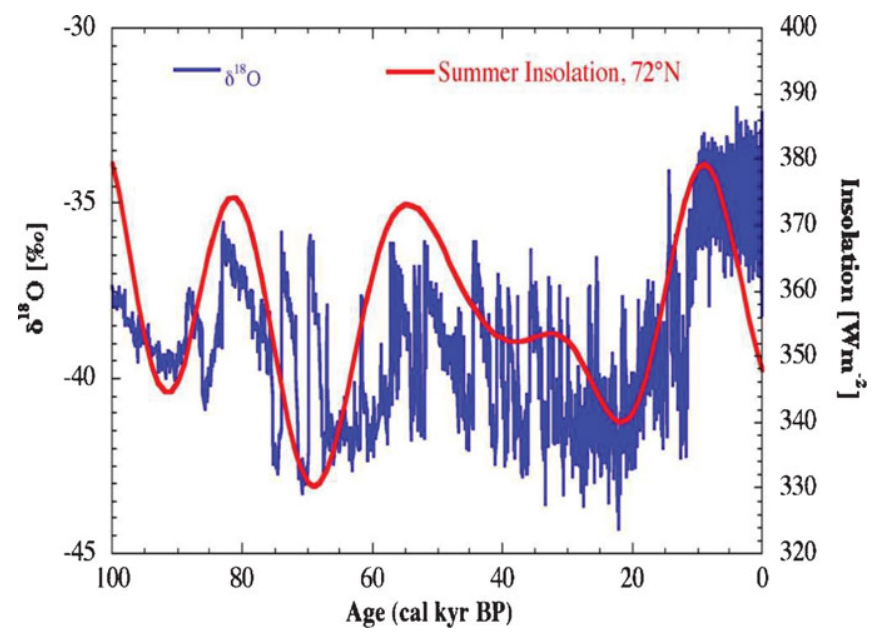

Figure 7. Comparison of the $\delta^{18} \mathrm{O}$ record from the GRIP ice core in central Greenland $\left(72^{\circ} \mathrm{N}\right)$ (Dansgaard et al. 1993) with the corresponding summer insolation for the past $100 \mathrm{kyr}$.

the aerosols can modify the radiative properties of clouds at low altitudes. The sources of aerosols are amongst others volcanic eruptions, dust from deserts, and anthropogenic activities such as burning of fossil fuel.

\subsection{Greenhouse gases}

Greenhouse gases $\left(\mathrm{H}_{2} \mathrm{O}, \mathrm{CO}_{2}, \mathrm{CH}_{4}\right.$ and others) let the sunlight with wave lengths in the range of 400-800 $\mathrm{nm}$ pass, but absorb the infrared radiation emitted by the Earth. As a result the lower atmosphere gets warmer. As we have already discussed, the Earth's temperature would be about $30^{\circ} \mathrm{C}$ lower without the natural greenhouse gas concentrations in the atmosphere. Due to the greenhouse effect the emission of the infrared radiation into space does not take place at the Earth's surface but is shifted higher up in the atmosphere where the temperature is about $-20^{\circ} \mathrm{C}$ according to formula (2.3). The greenhouse effect is very important to make the Earth habitable. It was even more crucial at the time when the solar luminosity was considerably lower (faint young sun paradox). However, since the industrialisation mankind has begun to burn large amounts of fossil fuel which is raising the atmospheric $\mathrm{CO}_{2}$ content to levels unprecedented during the past million years (Luthi et al. 2008). A good example for extreme greenhouse gas forcing is Venus. Its atmosphere consists almost entirely $(97 \%)$ of $\mathrm{CO}_{2}$ with clouds containing droplets of sulphuric acid heating the planet to $460^{\circ} \mathrm{C}$ (Table 1 ).

\section{Evidence for solar variability and climate change on Earth}

In this chapter we will provide some evidence for solar induced climate change on Earth. In the last decade the number of publications claiming a causal connection between solar variability and climate change was steadily increasing. Nevertheless, there always remains the problem of unequivocal attribution. We still do not know quantitatively how much the total and the spectral solar forcing changed in the past. Furthermore, we do not know how exactly the climate system responds to such forcings. Unquestionably, the climate is a complex non-linear system and even the most advanced general circulation models are far from representing realistically all the complex processes, their couplings, and feedback 
effects. A recent overview of the mid- to late Holocene climate change is given by Wanner et al. 2008. In the following, we present two examples, one from Switzerland and one from China.

\subsection{The Great Aletsch glacier}

One of the most striking ways to illustrate the ongoing global warming is to compare old photographs of glaciers with recent ones. The size of a glacier is strongly determined by the winter precipitation and the summer temperature. It is rather inert and does not respond immediately to single climatic events but records the climate changes averaged over the last few decades. By dating trees which were buried during glacier advances it is possible to reconstruct fluctuations in the length (Denton and Karlén 1973; Holzhauser, Magny, and Zumbühl 2005; Hormes, Beer, and Schluchter 2006; Joerin, Stocker, and Schluchter 2006).

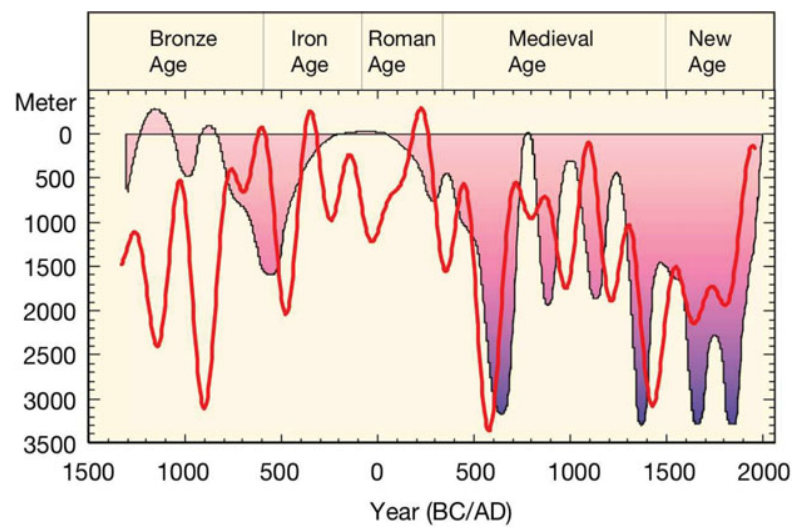

Figure 8. Comparison of the reconstructed length fluctuations of the Great Aletsch glacier (relative to its present length) in the Swiss Alps (Holzhauser, Magny, and Zumbühl 2005) with the solar activity record (Steinhilber, Abreu, and Beer 2008; Vonmoos, Beer, and Muscheler 2006). Low solar activity coincides generally with larger extensions of the glacier. Note that the dating of both the record of glacier length fluctuations and the record of solar activity has some uncertainties.

Fig. 8 shows the reconstruction of the length fluctuations of the Aletsch glacier, the largest glacier in the Alps (Holzhauser, Magny, and Zumbühl 2005). The length is given relative to today. The curve shows that the Aletsch glacier was longer during the little ice age (about 1350-1850 AD) by almost $3500 \mathrm{~m}$. However, the present situation is not unique. There were earlier periods when its length was comparable to todays length. These times coincide with warm epochs such as the Roman and the Medieval Warm Period. However, taking into account the delayed response the Aletsch glacier reflects not yet the global warming after 1970 and will therefore continue to melt in the future. The solar activity record is based on ${ }^{10} \mathrm{Be}$ measurements in polar ice cores. ${ }^{10} \mathrm{Be}$ is produced in the atmosphere by cosmic ray particles which are magnetically shielded on their way through the heliosphere depending on the solar activity (Beer, Vonmoos, and Muscheler 2006). This is a good example to illustrate the difficulties we face when we try to attribute a climate record to solar forcing: the solar activity record is not calibrated in $\mathrm{Wm}^{-2}$, the responses of the climate system in general and of the glacier length in particular are non-linear, the dating of the length fluctuations and the solar activity have uncertainties, 
and there are volcanic and other forcings involved as well. Nevertheless, we believe that the overall agreement points to a significant solar forcing.

\subsection{Speleothems in China}

Speleothems are formed of $\mathrm{CaCO}_{3}$. Ca is dissolved by rainwater percolating through the soil. Investigations of recent deposited $\mathrm{CaCO}_{3}$ shows that the $\delta^{18} \mathrm{O}$, the deviation of the ${ }^{18} \mathrm{O} /{ }^{16} \mathrm{O}$ ratio in $\mathrm{CaCO}_{3}$ from a standard, reflects the amount of precipitation. Using the $\mathrm{U} / \mathrm{Th}$ dating technique it is possible to determine the time of carbonate formation within a few years for the past 10,000 years.

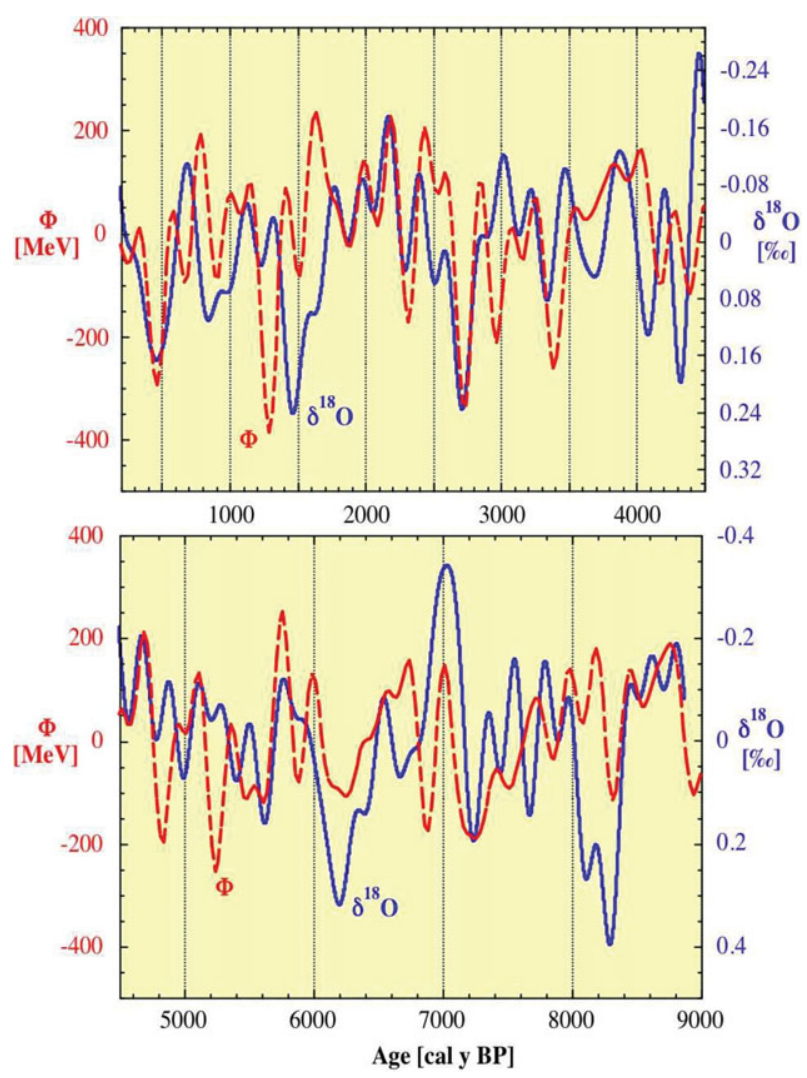

Figure 9. $\delta^{18} \mathrm{O}$ record of the Dongge cave in China (Dykoski et al. 2005) reflecting the intensity of monsoon (blue line) together with the solar activity record (red line). Both records are low-pass filtered with $200 \mathrm{y}$.

In Fig. 9 the $\delta^{18} \mathrm{O}$ record derived from a stalagmite in the Dongge cave in China (Dykoski et al. 2005) is compared with the same solar activity record as in Fig. 8. The Dongge cave is situated near the boundary of the present monsoon. The largest discrepancy occurs at $8200 \mathrm{BP}$ when a large amount of melt water entered the Atlantic reducing the thermohaline circulation (Clark et al. 2001). This event is not expected to be reflected in the solar activity record. Beside this event, the overall agreement between the two records also points to a causal relationship. This is corroborated by the fact that spectral analysis reveals common periodicities such as the 208-y de Vries or Suess cycle 
also known from the analysis of the ${ }^{14} \mathrm{C}$ calibration curve from tree rings (Stuiver and Braziunas 1993).

\section{Summary and conclusions}

To a large extent the climate of a planet is determined by the radiative energy it receives from the Sun and its distribution. Beside luminosity and albedo the main factor controlling the amount of received energy is the distance between the planet and the Sun. The distribution depends strongly on the existence of an atmosphere and oceans and their properties, but also on the orbital parameters of the planet (rotation, obliquity, precession). When it comes to climate variability potential causes are changes in the energy transport in the convective zone of the Sun, in the emission of the electromagnetic radiation from the photosphere, in the orbital parameters (Milankovic), and in the properties of the planet (albedo, aerosols, greenhouse gases, clouds, vegetation, energy transport etc.). Due to feedback mechanisms, the climatic effect of a change in forcing depends not only on its intensity $\left(\mathrm{Wm}^{-2}\right)$, but also on its distribution and duration. Predictions are therefore difficult and there are still many open questions. Nevertheless, as far as solar forcing on Earth is concerned there are some facts:

- The Sun is by far the most important source of energy for the climate system.

- The Sun is a variable star. Its irradiance is only well known for the past 30 years a period of high but relatively stable activity.

- The Sun has the potential for larger TSI variability although it is not yet clear to what extent it was used.

- The climate system was never stable. There were only periods of larger or smaller variability.

- The Holocene atmospheric $\mathrm{CO}_{2}$ concentration was rather constant before the industrialisation.

- Climate models show that any change in forcing (greenhouse gas, volcanic or solar) leads to responses of the climate system with complex spatial and temporal patterns which makes detection and attribution difficult.

- There is growing evidence that among other forcings the Sun plays a significant role in climate change.

\section{Acknowledgements}

We thank Petra Breitenmoser for useful comments. This work was financially supported by the Swiss National Science Foundation.

\section{References}

Beer, J., Vonmoos, M., \& Muscheler, R.: 2006, Solar Variability Over the Past Several Millennia. Space Science Reviews 125, 79-79. doi:10.1007/s11214-006-9047-4.

Berger, A. L.: 1978, Long-Term Variations of Daily Insolation and Quaternary Climatic Changes. Journal of Atmospheric Sciences 35, 2367-2367.

Bryden, H. L. \& Imawaki, S.: 2001, Ocean heat transport. In: Siedler, G., Church, J., Gould, J. (eds.) Ocean Circulation and Climate, Academic Press, St. Louis, 474-474.

Clark, P. U., Marshall, S. J., Clarke, G. K. C., Hostetler, S. W., Licciardi, J. M., \& Teller, J. T.: 2001, Freshwater Forcing of Abrupt Climate Change During the Last Glaciation. Science 293, 287 -287. doi:10.1126/science.1062517. 
Dansgaard, W., Johnson, S. J., Clausen, H. B., Dahl-Jensen, D., Gundestrup, N. S., Hammer, C. U., Hvidbjerg, C. S., Steffensen, J. P., Sveinbjörnsdottir, A. E., Jouzel, J., \& Bond, G.: 1993, Evidence for general instability of past climnate from a 250-kyr ice-core record. Nature 364, 220 - 220. doi:10.1038/364218a0.

Denton, G. H. \& Karlén, W.: 1973, Holocene climatic variations - their pattern and possible cause. Quaternary Research 3, 205-205.

Dykoski, C. A., Edwards, R. L., Cheng, H., Yuan, D., Cai, Y., Zhang, M., Lin, Y., Qing, J., An, Z., \& Revenaugh, J.: 2005, A high-resolution, absolute-dated Holocene and deglacial Asian monsoon record from Dongge Cave, China. Earth and Planetary Science Letters 233, 86-86. doi:10.1016/j.epsl.2005.01.036.

Fröhlich, C.: 2006, Solar Irradiance Variability Since 1978. Revision of the PMOD Composite during Solar Cycle 21. Space Science Reviews 125, 65-65. doi:10.1007/s11214-006-9046-5.

Fröhlich, C.: 2008, Total Solar Irradiance Variability: What have we learned about its variability from the record of the last three solar cycles? Proc. CAWSES Symp., October, 23-27 2007, Kyoto, Japan.

Fröhlich, C. \& Lean, J.: 2004, Solar radiative output and its variability: evidence and mechanisms. Astronomy and Astrophysicsr 12, 320-320. doi:10.1007/s00159-004-0024-1.

Holzhauser, H., Magny, M., \& Zumbühl, H. J.: 2005, Glacier and lake-level variations in westcentral Europe over the last 3500 years. Holocene 15, 801-801.

Hormes, A., Beer, J., \& Schluchter, C.: 2006, A geochronological approach to understanding the role of solar activity on Holocene glacier length variability in the Swiss Alps. Geografiska Annaler Series A - Physical Geography 88, 294-294.

Joerin, U. E., Stocker, T. F., \& Schluchter, C.: 2006, Multicentury glacier fluctuations in the Swiss Alps during the Holocene. Holocene 16, 704-704.

Kernthaler, S. C., Toumi, R., \& Haigh, J. D.: 1999, Some doubts concerning a link between cosmic ray fluxes and global cloudiness. Geophysical Research Letters 26, 866-866. doi:10.1029/1999GL900121.

Krivova, N. A., Solanki, S. K., Fligge, M., \& Unruh, Y. C.: 2003, Reconstruction of solar irradiance variations in cycle 23: Is solar surface magnetism the cause? Astronomy and Astrophysics 399, 4-4. doi:10.1051/0004-6361:20030029.

Kuhn, J. R.: 1988, Helioseismological splitting measurements and the nonspherical solar temperature structure. Astrophysical Journal Letters 331, 134-134. doi:10.1086/185251.

Kuhn, J. R. \& Libbrecht, K. G.: 1991, Nonfacular solar luminosity variations. Astrophysical Journal Letters 381, 37-37. doi:10.1086/186190.

Laskar, J., Robutel, P., Joutel, F., Gastineau, M., Correia, A. C. M. \& Levrard, B.: 2004, A long-term numerical solution for the insolation quantities of the Earth. Astronomy and Astrophysics 428, 285-285. doi:10.1051/0004-6361:20041335.

Lockwood, M., \& Fröhlich, C.: 2008, Recent oppositely directed trends in solar climate forcings and the global mean surface air temperature. II. Different reconstructions of the total solar irradiance variation and dependence on response time scale. Proceedings of the Royal Society 464, 1385-1385.

Luthi, D., Le Floch, M., Bereiter, B., Blunier, T., Barnola, U. J. M. Siegenthaler, Raynaud, D., Jouzel, J., Fischer, H., Kawamura, \& T. F. K. Stocker: 2008, High-resolution carbon dioxide concentration record 650,000-800,000 years before present. Nature 453, 382-382.

Marsh, N. \& Svensmark, H.: 2003, Solar Influence on Earth's Climate. Space Science Reviews 107, 325 - 325. doi:10.1023/A:1025573117134.

Milankovic, M.: 1930, Mathematische Klimalehre und atsronomische Theorie der Klimaschwankungen. In: Köppen, W., \& Geiger, R. (eds.) Handbuch der Klimatologie, Gebrüder Bornträger, Berlin, 176-176.

Newkirk, G. Jr.: 1983, Variations in solar luminosity. Annual review of astronomy and astrophysics 21, $467-467$. doi:10.1146/annurev.aa.21.090183.002241. 
Sofia, S. \& Li, L. H.: 2005, Mechanisms for global solar variability. Memorie della Societa Astronomica Italiana 76, 768.

Solanki, S. K. \& Fligge, M.: 2002, Solar irradiance variations and climate. Journal of Atmospheric and Solar-Terrestrial Physics 64, 685-685.

Steinhilber, F., Abreu, J. A., \& Beer, J.: 2008, Solar modulation during the Holocene. Astrophysics and Space Sciences Transactions 4, 6-6.

Stuiver, M. \& Braziunas, T. F.: 1993, Sun, Ocean, Climate and Atmospheric ${ }^{14} \mathrm{CO}_{2}$, an evaluation of causal and spectral relationships. Holocene 3, 305-305.

Svensmark, H.: 1998, Influence of Cosmic Rays on Earth's Climate. Physical Review Letters 81, $5030-5030$.

The Picard Team, Dewitte S. \& Schmutz W.: 2006, Simultaneous measurement of the total solar irradiance and solar diameter by the PICARD mission. Advances in Space Research 38, 1806 - 1806. doi:10.1016/j.asr.2006.04.034.

Thuillier, G., Sofia, S., \& Haberreiter, M.: 2005, Past, present and future measurements of the solar diameter. Advances in Space Research 35, 340-340. doi:10.1016/j.asr.2005.04.021.

Tinsley, B. A.: 2000, Influence of Solar Wind on the Global Electric Circuit, and Inferred Effects on Cloud Microphysics, Temperature, and Dynamics in the Troposphere. Space Science Reviews 94, 258-258.

Unruh, Y. C., Solanki, S. K., \& Fligge, M.: 1999, The spectral dependence of facular contrast and solar irradiance variations. Astronomy and Astrophysics 345, 642-642.

Usoskin, I. G., Marsh, N., Kovaltsov, G. A., Mursula, K., \& Gladysheva, O. G.: 2004, Latitudinal dependence of low cloud amount on cosmic ray induced ionization. Geophysical Research Letters 31, 16109. doi:10.1029/2004GL019507.

Vonmoos, M., Beer, J., \& Muscheler, R.: 2006, Large variations in Holocene solar activity: Constraints from ${ }^{10} \mathrm{Be}$ in the Greenland Ice Core Project ice core. Journal of Geophysical Research (Space Physics) 111(10), 10105. doi:10.1029/2005JA011500.

Wagner, G., Livingstone, D. M., Masarik, J., Muscheler, R., \& Beer, J.: 2001, Some results relevant to the discussion of a possible link between cosmic rays and the Earth's climate. Journal of Geophysical Research 106, 3388-3388. doi:10.1029/2000JD900589.

Wanner, H., Beer, J., Bütikofer, J., Crowley, T. J., Cubasch, U., Flückiger, J., Goosse, H., Grosjean, M., Joos, F., Kaplan, J. O., Küttel, M., Müller, S. A., Prentice, I. C., Solomina, O., Stocker, T. F., Tarasov, P., Wagner, M., \& Widmann, M.: 2008, Mid- to Late Holocene climate change: an overview. Quaternary Science Reviews 27, 1828-1828.

Wenzler, T., Solanki, S. K., Krivova, N. A., \& Fröhlich, C.: 2006, Reconstruction of solar irradiance variations in cycles 21-23 based on surface magnetic fields. Astronomy and Astrophysics 460, 595-595. doi:10.1051/0004-6361:20065752.

Willson, R. C., Mordvinov \& A. V.: 2003, Secular total solar irradiance trend during solar cycles 21-23. Geophysical Research Letters 30(5), 1-1. 


\section{Discussion}

BonneT: Thank you Juerg for an excellent presentation. I am pleased that the topic you discuss brings strong support to my point that space science in the future may face a difficult time when there will be tough competition for funds with Earth sciences: solar influences on the climate are clearly something to be studied more precisely and more continuously in the future. This is not to say that the whole of future heliospheric research should be referring to Sun Earth Climate relations. But there certainly is a connection between heliospheric science and the more immediate concerns of humans on Earth.

BEER: I fully agree with this statement.

BochSLER: Is it possible that people crossed the Schnidejoch at all times and climatic periods, but were more negligent during warm periods loosing plants, and other objects more frequently?

BEER: So far the findings clearly point to distinct periods when the snow and ice cover was low enough to cross this pass at almost 3000 m.a.s.l. 